\title{
Tarifas Equivalentes de Medidas não Tarifárias sobre Exportações Brasileiras de Carne Bovina para a UE (2000-2010)
}

\author{
Nathalia Sbarai ${ }^{1}$ e Sílvia Helena Galvão de Miranda² $^{2}$
}

\begin{abstract}
Resumo: Neste trabalho, estimam-se tarifas equivalentes para medidas não tarifárias (MNTs) aplicadas ao comércio de carne bovina (fresca e congelada, com osso ou desossada) entre Brasil e União Europeia, para o período de 2000 a 2010. A revisão de literatura identifica um número considerável de exigências técnicas e sanitárias incidentes sobre o comércio de carne. Estima-se um modelo, assumindo homogeneidade e heterogeneidade entre os bens, seguindo a metodologia proposta por Yue, Beghin e Jensen (2005). Em geral, observam-se tarifas equivalentes elevadas, i.e., os preços domésticos europeus e os preços mundiais diferem, o que pode indicar que o mercado da UE está sendo protegido por medidas não tarifárias.
\end{abstract}

Palavras-chaves: Medidas técnicas, medidas sanitárias, método do price-wedge, tarifas equivalentes, heterogeneidade, carne bovina.

\begin{abstract}
In this paper, tariff equivalent of NTMs are estimated considering the beef trade (frozen and fresh beef, bone and boneless) between Brazil and the EU, for the period from 2000 to 2010. The literature review points out a considerable number of requirements that affect beef trade. A model is estimated, assuming homogeneity and heterogeneity of goods, and following the methodology proposed by Yue, Beghin and Jensen (2005). In general, high values for the tariff equivalents are observed, i.e., the European domestic prices and the world prices actually differ, which could indicate that the European beef market has been protected by NTMs.
\end{abstract}

Key-words: Technical measures, sanitary measures, price-wedge method, tariff equivalent, heterogeneity, beef.

Classificação JEL: F19.

1. ESALQ/USP. Doutoranda em Economia Aplicada. E-mail: nathalia.sbarai@usp.br

2. ESALQ/USP. Professora do Departamento de Economia, Administração e Sociologia. E-mail: shgdmira@usp.br 


\section{Introdução}

A questão das medidas não tarifárias (MNTs) é discutida pela primeira vez nas negociações da Rodada Tóquio (1973-1979), ainda no contexto do Acordo Geral de Tarifas e Comércio (GATT, sigla em inglês). Por MNTs entende-se uma ampla e heterogênea gama de intervenções políticas, que não sejam tarifas e que afetem e distorçam o comércio de bens, serviços e fatores de produção ${ }^{3}$ (BEGHIN, 2006).

Cria-se, nesse contexto da Rodada, o Standards Code, que regula a aplicação dessas medidas, a fim de garantir que regulamentações, padrões, procedimentos de teste e de certificação não criem obstáculos desnecessários ao comércio. No entanto, Lima e Barral (2007) afirmam que esse código mostrava-se limitado quanto a requisitos para os produtos agrícolas, de modo que, com a criação da Organização Mundial do Comércio (OMC), em 1995, foram firmados o Acordo sobre Barreiras Técnicas ao Comércio (TBT) e o Acordo sobre a Aplicação de Medidas Sanitárias e Fitossanitárias (SPS), em substituição ao Standards Code.

Esses acordos apresentam grande destaque no contexto atual de comércio internacional, uma vez que, com a restrição ao uso de quotas e a limi-

3. Essa definição pode variar de acordo com diferentes autores. Beghin e Bureau (2001) apresentam breve discussão sobre essa questão. tação do uso de medidas tarifárias acordada na Rodada Uruguai, verifica-se um aumento da utilização de MNTs, sendo adotadas com maior frequência medidas técnicas e sanitárias. Segundo a $\mathrm{UNCTAD}^{4}$ (2005), a incidência no uso de medidas tarifárias passa de 5,8\% do total de linhas tarifárias em 1994, para 0,3\% em 2004; enquanto a utilização de medidas de controle de quantidades (quotas) também se reduz de 49,2\% do total, em 1994, para 34,8\%, em 2004. Por outro lado, a imposição de medidas técnicas aumenta de 31,9\%, em 1994, para 58,5\% das linhas tarifárias, em 2004, ampliando-se as exigências impostas a países exportadores.

A imposição de medidas técnicas e sanitárias acarreta impactos sobre o comércio, independentemente de ter o objetivo de proteger o mercado ou de corrigir ineficiências, e pode gerar choques também na estrutura produtiva dos bens afetados. Mais além, os efeitos potenciais de inibição do comércio dessas regulamentações constituem-se em um desafio principalmente para os países em desenvolvimento que buscam aumentar a produção para mercados de exportação (MASKUS e WILSON, 2001). Assim, as exigências relativas ao acesso de produtos importados, como aspectos sanitários, rastreabilidade e outras questões, como as ambientais, afetam os fluxos comerciais do Brasil (MIRANDA e BARROS,

4. United Nations Conference on Trade and Development. 
2009). Dentre os produtos mais afetados por esses tipos de medidas, destacam-se as carnes. De fato, Kassum e Morgan (2002) afirmam que os produtos de origem animal respondem por uma parte importante das notificações do Acordo SPS à OMC, tendo representado uma média de $31 \%$ do total de medidas sanitárias impostas no período entre 1995 e 2001, com quase metade dessas notificações originando-se nos EUA, Nova Zelândia, México, Comunidade Europeia, Chile e Canadá, todos relevantes no mercado mundial da carne.

Diante do exposto, devido às restriçóes impostas aos produtos agropecuários brasileiros e, particularmente, à carne bovina, e à dificuldade de se obter a magnitude de proteção das medidas sanitárias e técnicas, tem-se como objetivo neste trabalho analisar os impactos das medidas sanitárias e técnicas aplicadas pela União Europeia sobre a exportação de carne bovina brasileira, através da obtenção de tarifas equivalentes. Adota-se, para isso, uma adaptação da metodologia do price-wedge considerando heterogeneidade do produto, proposta por Yue, Beghin e Jensen (2005), obtendo-se, então, uma tarifa equivalente, ou seja, uma alíquota de imposto de importação que restringiria o comércio ao mesmo nível que o conjunto de medidas não tarifárias existente.

Este artigo apresenta quatro seções, além desta introdução. Na próxima, apresenta-se uma revisão bibliográfica. Na seção 3, é explicitada a fundamentação teórica do artigo. Na seguinte, a metodologia e os dados utilizados são apresentados. E, por fim, as duas últimas seções destacam os resultados e as conclusões.

\section{Revisão bibliográfica}

A produção mundial de carne bovina corresponde, em 2011, a aproximadamente 22,8 milhões de toneladas em peso líquido, segundo o USDA. Destaca-se, com relação à produção mundial, que os produtores de carne bovina são classificados em categorias em virtude do seu status sanitário, sendo uma das classificações aquela de países aftósicos e não aftósicos. Dentre os países não aftósicos, destacam-se os Estados Unidos (maior produtor mundial, responsável por $21 \%$ da produção total de carne bovina em 2011), Canadá, Japão, Coreia do Sul, Nova Zelândia e Austrália.

O Brasil ocupava a terceira posição até 2004, e a partir de 2005 passa a ser o segundo maior produtor mundial de carne bovina, ultrapassando a União Europeia, destacado parceiro do Brasil no comércio de carne bovina: em 2001, a UE é destino de $34 \%$ do volume total das exportações brasileiras de carne bovina e, em 2011, passa a responder por apenas 5,91\%. Isso pode ser observado na Figura 1.

Figura 1. Exportação brasileira de carne bovina fresca e congelada total e para a União Europeia, em mil toneladas. De 2000 a 2011

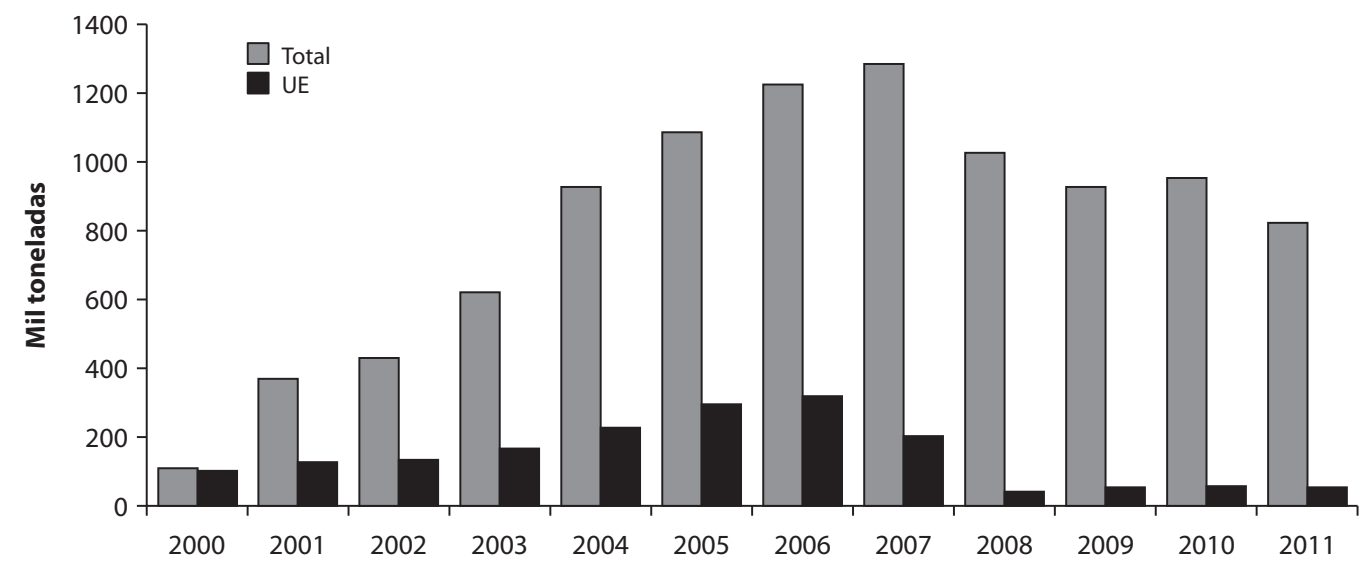

Fonte: MDIC e UN Comtrade, elaborado pelas autoras. 
Apesar da redução da importância relativa desse fluxo bilateral, a UE ainda representa um importante mercado importador dos produtos brasileiros, e que se caracteriza pela imposição de uma série de exigências (normalmente medidas técnicas ou sanitárias) com relação a esses produtos, que visam garantir a segurança do alimento e prevenir a disseminação de doenças animais, como a febre aftosa, no rebanho europeu. Nesse contexto, a UE proíbe a importação de carne com osso do Brasil, afirmando que os ossos poderiam propagar a aftosa. De fato, em 2011, o Brasil exporta apenas carne desossada, fresca ou refrigerada, e congelada, que correspondem, respectivamente, nesse ano, a 38,97\% e $61,03 \%$ do total brasileiro exportado para a UE.

Schlueter e Wieck (2009) afirmam, ainda, que a UE é a maior responsável pela imposição de medidas sanitárias no comércio de carne bovina dentre os 10 maiores importadores analisados em seu estudo, entre 1996 e 2007, sendo seguida pelos Estados Unidos e China. As medidas sanitárias impostas pela UE como regulamentos para os países-membros, mas que se estendem a todos os países que comercializam com o bloco, referem-se principalmente a níveis toleráveis de resíduos de produtos veterinários na carne bovina e seus derivados e subprodutos e a medidas preventivas de doenças e pragas. Kassum e Morgan (2002) identificam que, de 1995 a 2001, 60\% do total de notificações ao SPS tinham como objetivo garantir a saúde animal, e grande parte delas era relacionada à doença da vaca-louca e à febre aftosa.

Adicionalmente, observam-se exigências de controle do uso de fertilizantes, produtos veterinários e insumos para produção agrícola, exigindo que os produtores mantenham registros desses insumos. Um exemplo é a European Council Regulation 2.377/90, que estabelece níveis máximos de resíduo de medicamentos veterinários contidos na alimentação animal (ASHMEAD, 2008).

Além disso, a Diretiva Comunitária n. 46 de 1992 exige que praticamente todos os produtos de origem animal importados pela UE sejam provenientes de estabelecimentos habilitados pela Comissão Europeia; no entanto, esse processo de habilitação é lento, criando barreiras à exportação de carnes por novos estabelecimentos (MDIC, 2001?). Complementarmente, a Diretiva da União Europeia ECC 92/116, referente a todos os tipos de carne e seus derivados, exige a inspeção dos animais antes, durante e depois do abate, considerando os padrões exigidos de higiene, sanidade, processo, entre outras exigências (CUNHA FILHO, 2006).

Mais recentemente, em 2000, novos regulamentos europeus foram estabelecidos, com alto potencial de afetar os fornecedores brasileiros de carne. O regulamento CE n. 1760, modificado posteriormente pelo regulamento $\mathrm{CE}$ n. 1825/2000, estabelece que os animais devem ser individualmente identificados por meio de marcadores auriculares em ambas as orelhas, determina a implantação de uma base de dados informatizada nacional e implanta o sistema de rotulagem da carne, com informações sobre a carne e o local de origem e de abate do animal (PITELLI, 2004). Estes regulamentos tiveram desdobramentos importantes para a definição do sistema de rastreabilidade bovina no Brasil.

Além das exigências de rastreabilidade, observa-se ainda o aumento de requisitos sociais, que refletem a preocupação dos consumidores com questões sociais e levam-nos a preferir animais que sejam tratados com cuidado e de maneira a causar menor impacto sobre o meio ambiente (ASHMEAD, 2008).

Assim, conclui-se que a carne bovina é alvo de um conjunto amplo de regulamentações técnicas e sanitárias, referentes à saúde animal, uso de produtos veterinários, rastreabilidade, bem-estar social, bem-estar animal, entre outras, que criam um ambiente de complexidade regulatória. Marcado por normas e regulamentos, além de preferências de consumidores que variam significativamente entre países, esse ambiente acaba por afetar os fluxos internacionais do produto analisado.

Maskus e Wilson (2001) afirmam que regulamentações técnicas impostas sobre produtos comercializados afetam os padrões de comércio vigentes, a habilidade de os produtores entra- 
rem em novos mercados e os custos ao consumidor. No entanto, esses autores enfatizam que existe pouca evidência empírica sobre o impacto de regulamentos técnicos e comércio, embora, diante dessa discussão, diversos autores tenham se proposto a mensurar a imposição desses regulamentos, dentre os quais destaca-se Kee, Nicita e Olarreaga (2008) e Disdier, Fontagné e Mimouni (2007), que utilizaram medidas de impactos quantitativos para essa mensuração, Miranda e Barros (2009) e Mendes, Coelho e Campos (2009), que realizaram a mensuração por um modelo de intervenção, Souza e Burnquist (2008), que fizeram uma análise fatorial dos dados e, por fim, destaca-se o trabalho de Deardorff e Stern, que apresentam ampla revisão sobre os modelos utilizados para mensuração de MNTs.

É claro, na literatura, que tarifas e quotas elevam os custos aos consumidores, alocam os recursos de forma ineficiente e resguardam o poder de mercado das empresas nacionais no âmbito doméstico, o que é comprovado por diversos estudos que afirmam que a sua eliminação ou redução gera um benefício mútuo aos países envolvidos (MASKUS e WILSON, 2001). Contudo, segundo os autores, com relação às medidas técnicas (e sanitárias - nota das autoras), cujos objetivos são importantes à comunidade em geral, como garantir a saúde pública ou proteção ambiental, sua eliminação poderia gerar perdas sociais maiores que os possíveis ganhos de eficiência econômica.

Contudo, independente da finalidade observada na aplicação das medidas técnicas e sanitárias, elas gerarão efeitos sobre o comércio, refletidos principalmente, conforme observado em Roberts, Josling e Orden (1999), sobre os preços, que se elevam em virtude do incremento nos custos, causado pela incorporação de um custo de cumprimento das medidas impostas. Essa elevação dos preços é responsável, então, pela alteração da quantidade produzida, consumida e comercializada, de modo que é possível utilizá-la para estimar o impacto das medidas sobre o comércio. Assim, utiliza-se o método do price-wedge, apresentado a seguir, para, através das diferenças nos preços, obter tarifas equivalentes para as MNTs, ou seja, para obter tarifas que restringem o comércio no mesmo nível que as MNTs observadas. Esse artigo segue a metodologia proposta por Yue, Beghin e Jensen (2005), para as exportações de maçã dos Estados Unidos para o Japão, e que também foi utilizada por Nimenya (2009), para o caso de comércio de alguns produtos agrícolas entre UE e África.

\section{Fundamentação teórica}

O método price-wedge baseia-se, segundo Beghin e Bureau (2001), na ideia de que uma MNT pode ser aferida em termos do seu impacto sobre o preço doméstico de um bem no mercado importador $\left(P_{i}\right)$ em relação a um preço de referência, usualmente o preço mundial $\left(\mathrm{P}_{\mathrm{i}}^{*}\right)$, de um bem comparável. De acordo com Deardorff e Stern (1997), como o impacto no preço é uma propriedade geral das MNTs, uma comparação de preços pode mostrar os efeitos líquidos dessas medidas, sem ser necessário identificá-las. Tal comparação poderia, então, ser apresentada através da diferença percentual entre eles, de maneira comparável a uma tarifa.

$$
\mathrm{T}=100 \times \frac{\left\lfloor\mathrm{P}_{\mathrm{i}}-\mathrm{P}_{\mathrm{i}}^{*}\right\rfloor}{\mathrm{P}_{\mathrm{i}}^{*}}
$$

A partir da eq. (1), gera-se uma tarifa equivalente para as MNTs, ou seja, obtém-se uma alíquota de tarifa que restringiria o comércio na mesma intensidade que a MNT existente. Essa MNT pode ser uma quota, uma medida sanitária ou técnica, por exemplo, ou um conjunto dessas medidas incidindo simultaneamente.

A eq. (1) apresenta a tarifa implícita pelo efeito de uma MNT somente quando os bens importados e domésticos combinados em $P_{i}$ são substitutos perfeitos, de forma que são vendidos ao mesmo preço no mercado doméstico (DEARDORFF e STERN, 1997). Assim, uma vez que a metodologia do price-wedge baseia-se na comparação de preços, é necessário pressupor a inexistência de outros fatores significativos que 
contribuam com a diferença de preço observada (CALVIN e KRISSOFF, 1998).

No entanto, Andriamananjara et al. (2004) afirmam que a variação de preços de produtos entre países deve-se a diversos fatores, sendo que as MNTs representam apenas um deles. Dessa forma, devem ser considerados os custos necessários para a exportação do bem no cálculo da tarifa equivalente. Caso ainda seja observada diferença de preços entre bens equivalentes em dois países distintos, pode-se afirmar que o mercado com maior preço é protegido (BRADFORD, 2003). Dentre esses custos, incluem-se tarifas de importação que, caso existam, devem ser extraídas da tarifa equivalente obtida, a fim de obter-se apenas a tarifa representativa da dimensão das MNTs.

Destaca-se, ainda, que essa metodologia apresenta melhores resultados para produtos homogêneos, visto que, para esses, o preço CIF de importação pode ser observado diretamente ou construído a partir do preço de um mercado mundial unificado (DEARDORFF e STERN, 1997). Além disso, diferenças de preços entre produtos podem ser decorrentes de distinções na qualidade desses, de modo que o método do price-wedge, aplicado para analisar mercados de produtos não homogêneos, poderia identificar protecionismo onde esse, de fato, não existe, ao desconsiderar o efeito do diferencial da qualidade sobre os preços analisados (BEGHIN e BUREAU, 2001). Em virtude dessas limitações no método do price-wedge, Yue, Beghin e Jensen (2005) buscam adaptá-lo a fim de ampliar sua abrangência, tornando os resultados obtidos mais representativos dos mercados analisados, por meio da incorporação de diferenças na qualidade dos produtos comercializados, ou seja, considerando-se que os produtos são heterogêneos entre si.

Assim, Yue, Beghin e Jensen (2005) derivam um modelo para estimação de tarifa equivalente de medidas técnicas, relaxando o pressuposto de homogeneidade dos bens e incorporando, em seguida, custos de comércio (tais como transporte), para o caso do fluxo de maçãs entre Estados Unidos (EUA) e Japão. Para incorporar a heterogeneidade dos bens na preferência dos consumidores e para, eventualmente, estimar a tarifa equivalente de uma barreira técnica e sanitária (nota das autoras), os autores utilizaram um modelo simples de elasticidade de substituição constante (CES).

Yue, Beghin e Jensen (2005) assumem o caso de um país pequeno, cujas importações enfrentam um preço mundial exógeno. Nesse caso, o preço $\left(\mathrm{p}_{\mathrm{D}}\right)$ do bem doméstico é determinado pelo equilíbrio do mercado do bem doméstico, obtido a partir da maximização da função utilidade (U) de um consumidor representativo, sujeito a uma restrição orçamentária, conforme indicado nas eq. (2) e (3).

$$
\begin{aligned}
& \operatorname{Max}\left(\mathrm{I}(\mathrm{D}, \mathrm{I})=\left[\alpha \mathrm{D}^{\rho}+(1-\alpha) \mathrm{I}^{\rho}\right]^{1 / \rho}+\mathrm{AOG}\right. \\
& \text { s.t. } \mathrm{p}_{\mathrm{D}} \mathrm{D}+\mathrm{p}_{\mathrm{I}} \mathrm{I}+\mathrm{AOG}=\mathrm{M}_{\mathrm{T}}
\end{aligned}
$$

Em que $\mathrm{M}_{\mathrm{T}}$ é o gasto com os bens domésticos e importados, $\alpha$ e $\rho$ são parâmetros que refletem as preferências, e $\mathrm{p}_{\mathrm{D}}$ e $\mathrm{p}_{\mathrm{I}}$ são os preços ao consumidor dos bens doméstico e importado, D e I representam as quantidades de bens domésticos e importados, respectivamente, e AOG, o numeraire agregado do bem (YUE, BEGHIN e JENSEN, 2005).

Essa maximização permite a obtenção de uma equação que relaciona o preço dos bens importados à preferência do consumidor e à substituição de Armington entre os bens, conforme apresentado na eq. (4):

$$
\mathrm{p}_{\mathrm{I}}=\mathrm{p}_{\mathrm{D}} \frac{(1-\alpha)}{\alpha}\left(\frac{\mathrm{D}}{\mathrm{I}}\right)^{1 / \sigma}
$$

Em que $\sigma_{\mathrm{i}}=1 /(1-\rho)$ é a elasticidade de substituição entre o bem importado e o doméstico. Além disso, Yue, Beghin e Jensen (2005) afirmam que a imposição de medidas técnicas leva a um aumento do custo marginal de produção e de processamento. Consequentemente, o preço de importação $\left(\mathrm{p}_{\mathrm{I}}\right)$ é expresso como na eq. (5):

$$
\begin{aligned}
& \mathrm{p}_{\mathrm{I}}=\mathrm{p}^{*}+\mathrm{TBT}_{1}+\mathrm{TBT}_{2}+\mathrm{IT}_{\mathrm{R}}+\text { Tariff }+\mathrm{T}_{\mathrm{R}}= \\
& =\mathrm{p}^{*}+\mathrm{TBT}_{\mathrm{T}}+\mathrm{IT}_{\mathrm{R}}+\text { Tariff }+\mathrm{T}_{\mathrm{R}}
\end{aligned}
$$

Na eq. (5), no estudo dos autores, $\mathrm{p}^{*}$ representa o preço (ou custo) das maçãs norte-ameri- 
canas sendo vendidas em outro lugar que não no Japão, $\mathrm{IT}_{\mathrm{R}}$ é o custo de transporte, seguro e outros custos da comercialização internacional das maçãs exportadas para o Japão, Tariff é a tarifa de importação específica, $\mathrm{T}_{\mathrm{R}}$ é o custo de transporte e de transação por unidade, do porto do país de destino até o mercado interno atacadista. A variável $\mathrm{TBT}_{\mathrm{T}}$ corresponde à tarifa equivalente das medidas técnicas (e/ou sanitárias, nota das autoras), que compreende dois componentes do TBT: $\mathrm{TBT}_{1}$ representando os requisitos técnicos incidentes sobre a produção do produto (maçãs) e $\mathrm{TBT}_{2}$, os requisitos impostos a partir da chegada do produto no país de destino, ao longo do canal de comercialização, até chegar ao consumidor (YUE, BEGHIN e JENSEN, 2005).

Ao isolar $\mathrm{TBT}_{\mathrm{T}}$ do lado esquerdo da equação e considerar o primeiro elemento do lado direito como a expressão do preço de importação ( $\mathrm{p}_{\mathrm{I}}$ na eq. 4) derivado a partir da maximização da utilidade, segundo os autores, obtém-se essa tarifa equivalente $\left(\mathrm{TBT}_{\mathrm{T}}\right)$ da seguinte forma:

$\mathrm{TBT}_{\mathrm{T}}=\mathrm{p}_{\mathrm{D}} \frac{1-\alpha}{\alpha}\left(\frac{\mathrm{D}}{\mathrm{I}}\right)^{\frac{1}{\sigma_{\mathrm{I}}}}-\mathrm{p}^{*}-\mathrm{IT}_{\mathrm{R}}-$ Tariff $-\mathrm{T}_{\mathrm{R}}$

Em que $p_{D}$ é o preço do bem doméstico, $\sigma_{\mathrm{i}}$ é a elasticidade de substituição, $\alpha$ e $\rho$ são parâmetros que refletem as preferências, e D e I representam as quantidades de bens domésticos e importados, respectivamente (YUE, BEGHIN e JENSEN, 2005). Essa equação pode assumir diferentes níveis de preferência e de substituição entre os bens; para assumir substituição perfeita entre os bens e consumidores, portanto, indiferentes a consumir o bem doméstico ou o bem importado, assume-se $\alpha=1 / 2$ e $\sigma_{\mathrm{i}} \rightarrow \infty$.

Trabalhando a eq. (6), os autores apresentam a expressão para obtenção da tarifa equivalente ad valorem, transcrita a seguir:

$$
\mathrm{TBT}_{\mathrm{T}}^{\%_{\mathrm{o}}}=\frac{\mathrm{p}_{\mathrm{D}}}{\mathrm{p}_{\mathrm{CIF}}} \frac{1-\alpha}{\alpha}\left(\frac{\mathrm{D}}{\mathrm{I}}\right)^{\frac{1}{\sigma_{\mathrm{i}}}}-\frac{\mathrm{p}^{*}}{\mathrm{p}_{\mathrm{CIF}}}-\mathrm{it} \mathrm{t}_{\mathrm{R}}-\mathrm{t}-\mathrm{t}_{\mathrm{R}}
$$

Na eq. (7), t é a tarifa de importação ad valorem, it $t_{\mathrm{R}}$ é a tarifa equivalente ad valorem do custo de transporte internacional, seguro e custo de transação, $t_{\mathrm{R}}$ é o custo de transporte e de transação internos, e p $\mathrm{P}_{\mathrm{CIF}}$ é o preço CIF.

Entretanto, não se espera observar essas pressuposições nas condições reais de comércio, de modo que os preços do bem doméstico e importado serão diferentes devido a diferenças na qualidade e à existência de substituição imperfeita. Assim, a fim de mensurar a sensibilidade de $\mathrm{TBT}_{\mathrm{T}}$ para preferência/qualidade, substituição imperfeita e custo de transporte, os autores calculam as elasticidades-sensibilidade da estimativa da tarifa equivalente com relação a $\sigma_{\mathrm{i}}, \alpha$ e aos custos de transporte.

Assim, para incorporar a heterogeneidade no método do price-wedge, é necessária a elasticidade de substituição entre o bem produzido domesticamente e o importado, e esta deve ser previamente estimada, tendo em vista que não está disponível em literatura. Gallaway, McDaniel e Rivera (2003) afirmam que esse grau de substituição é comumente chamado de elasticidade de Armington, em virtude de a especificação de elasticidade de substituição constante (CES) para elasticidade-substituição do comércio ser derivada de Armington (1969). De acordo com os autores, um elemento importante da abordagem de Armington é o pressuposto de que os consumidores distinguem os produtos de acordo com sua origem.

Destaca-se, neste ponto, que este artigo analisa especificamente o setor de carne bovina, visto que esse é alvo de uma série de medidas, como já destacado. Além disso, embora seja um setor agropecuário, nos quais, em geral, observam-se produtos homogêneos, especificamente para a carne bovina há diferenciação do produto com relação à qualidade e origem, por isso, opta-se por estimar a tarifa equivalente considerando heterogeneidade.

Tourinho, Kume e Pedroso (2002) demonstram como a demanda interna é atendida por um bem resultante de uma agregação CES entre bens domésticos e importados, conforme mostra a eq. 8:

$$
\mathrm{Q}_{\mathrm{i}}=\overline{\mathrm{Q}_{\mathrm{i}}}\left[\alpha_{\mathrm{i}} \mathrm{q}_{\mathrm{ii}}^{-\rho_{\mathrm{i}}}+\left(1-\alpha_{\mathrm{i}}\right) \mathrm{q}_{\mathrm{Di}}^{-\mathrm{p}_{\mathrm{i}}}\right]^{-1 / \rho_{\mathrm{i}}}
$$


Em que $Q_{i}, q_{I i}$ e $q_{D i}$ representam, respectivamente, os índices de quantidade do bem agregado, do produto importado e do bem produzido domesticamente do setor $i, \overline{\mathrm{Q}}_{\mathrm{i}}$ representa o fator de escala e $\alpha_{i}$ e $\rho_{\mathrm{i}}$ são parâmetros. O primeiro parâmetro indica o fator de distribuição, ou seja, quanto do bem agregado terá origem no mercado doméstico e quanto será importado. O segundo parâmetro traduz o formato da curva de indiferença, indicando o grau de substituição entre os produtos importado e doméstico (TOURINHO, KUME e PEDROSO, 2002).

A composição ótima entre os bens de diferentes origens é dada pela solução do problema de minimização do custo de demanda total, dados o dispêndio e os preços dos produtos importado e doméstico (TOURINHO, KUME e PEDROSO, 2002). O resultado obtido, mostrando a distribuição da demanda total entre os bens doméstico e importado, é apresentado a seguir.

$$
\frac{\mathrm{q}_{\mathrm{Ii}}}{\mathrm{q}_{\mathrm{Di}}}=\left(\frac{\alpha_{\mathrm{i}}}{1-\alpha_{\mathrm{i}}} \frac{\mathrm{p}_{\mathrm{Di}}}{\mathrm{p}_{\mathrm{Ii}}}\right)^{\sigma_{\mathrm{i}}}
$$

Pela eq. 9, verifica-se que a proporção entre a quantidade de bens domésticos e importados depende da razão entre os respectivos preços, $\mathrm{p}_{\mathrm{Di}} \mathrm{e}$ $\mathrm{p}_{\mathrm{Ii}}$, e da elasticidade de substituição $\sigma_{\mathrm{i}}=1 /\left(1+\rho_{\mathrm{i}}\right)$.

A partir da eq. (9), utiliza-se o logaritmo para obter uma relação entre quantidade relativa e preço relativo, em que a elasticidade de substituição é dada pela inclinação:

$\log \left(\frac{\mathrm{q}_{\text {Iit }}}{\mathrm{q}_{\text {Dit }}}\right)=\sigma_{\mathrm{i}} \log \left(\frac{\alpha_{\mathrm{i}}}{1-\alpha_{\mathrm{i}}}\right)+\sigma_{\mathrm{i}} \log \left(\frac{\mathrm{p}_{\text {Dit }}}{\mathrm{p}_{\text {Iit }}}\right)+\varepsilon_{\text {it }}$

Em que $\sigma_{\mathrm{i}} \log \left(\frac{\alpha_{\mathrm{i}}}{1-\alpha_{\mathrm{i}}}\right)$ é uma constante e $\sigma_{\mathrm{i}}$ é a elasticidade de substituição de Armington entre bens importados e domésticos.

\section{Material e métodos}

Para a estimação das Tarifas Equivalentes (TE) das MNTs para a carne, assumindo a heterogeneidade dos bens, é utilizada a eq. 7, apresentada na seção anterior, para o período de 2000 a
2010, período cuja escolha foi limitada pela disponibilidade de dados. No entanto, destaca-se que, para o caso apresentado neste artigo, não se inclui a tarifa de importação ad valorem ( $\mathrm{t}$ ) na equação, pois os dados de importação coletados estão medidos em valores CIF e não incluem o montante relativo a essas tarifas, nem o custo de transporte e de transação internos $\left(t_{R}\right)$, visto que se analisam valores no porto do país de destino.

Os dados de comércio referem-se a produtos agregados a 6 dígitos, conforme o Sistema Harmonizado de nomenclatura ${ }^{5}$. Os produtos analisados estão identificados a seguir: carnes de bovino (carcaças ou meias-carcaças), frescas ou refrigeradas (0201.10); carnes de bovino (outras peças não desossadas), frescas ou refrigeradas (0201.20); carnes de bovino desossadas, frescas ou refrigeradas (0201.30); carnes de bovino (carcaças ou meias-carcaças), congeladas (0202.10); carnes de bovino (outras peças não desossadas), congeladas (0202.20); carnes de bovino desossadas, congeladas (0202.30).

As elasticidades de substituição de Armington são estimadas entre a carne doméstica europeia e a importada do Brasil, por meio da eq. 10, tendo-se escolhido a União Europeia como mercado de destino para o estudo das tarifas equivalentes dada sua importância como importador e sua política de imposição de requisitos sanitários e técnicos.

Para a estimação, utiliza-se a quantidade importada mensal de carne bovina pela UE-27 com origem em países do bloco e com origem no Brasil, discriminada até o quarto dígito do $\mathrm{SH}$, ou seja, para os códigos 0201 e 0202, que representam, respectivamente, carnes bovinas frescas e carnes bovinas congeladas.

Além disso, toma-se o valor médio unitário dessas importações, obtido por meio da divisão dos valores da importação pela quantidade

5. Viegas (2003) ressalta que a opção por esta agregação pode causar distorções na análise, pois há exigências que incidem apenas sobre algumas linhas tarifárias designadas a 8 dígitos. Deste modo, ao trabalhar a 6 dígitos, considera-se que a barreira (ou MNT) incide sobre todos os produtos sob esta classificação, superestimando sua presença. 
importada, como proxy do preço doméstico, uma vez que não estão disponíveis estatísticas de preço doméstico de carne a esse nível de desagregação dos produtos para o bloco europeu. Para transformar os valores em dólar, utiliza-se a taxa de câmbio média mensal. Foram usados dados nominais para cálculo da tarifa equivalente ano a ano.

Para a estimação da TE, ao nível de desagregação escolhido não é possível identificar preços mundiais ou preços domésticos para a estimação das tarifas equivalentes, assim, opta-se por utilizar proxies. Para representar o preço doméstico no país importador (UE) para o produto i, representado na equação como $\mathrm{p}_{\mathrm{D}}$, utiliza-se o valor médio unitário por quilograma, obtido a partir da divisão do valor total das importações de i pela UE pela quantidade dessas. Utiliza-se o valor médio unitário das importações como proxy para o preço médio doméstico, assumindo-se que as firmas não têm capacidade de discriminar os preços, de modo que os bens são vendidos no mercado doméstico ou internacional aos mesmos valores.

Como proxy do preço CIF para o bem i ( $\left.\mathrm{p}_{\mathrm{CIF}}\right)$, toma-se o valor médio unitário por quilograma das importações dos 50 principais países compradores dos respectivos bens i, ponderado pelo valor de comércio. Estes 50 países representaram, em 2009, mais de 95\% das importações de carne bovina para todo i analisado. Como proxy do preço mundial para o bem i $\left(\mathrm{p}^{*}\right)$, toma-se o valor médio unitário por quilograma das importações dos principais países compradores (com exceção dos países da UE) dos respectivos bens i, com origem no Brasil, ponderado pelo valor de comércio.

Para a estimação necessita-se também do volume de venda dos produtos domésticos e do volume de produtos importados (D e I, respectivamente) de modo a calcular a relação de consumo entre os bens produzidos domesticamente e os importados. Como não foi encontrada uma série de volume de vendas de carne bovina produzida domesticamente na União Europeia, uma aproximação foi obtida extraindo-se da produção total as exportações líquidas. No entanto, em virtude da indisponibilidade de dados de produ- ção classificados de acordo com o SH, utilizam-se a produção total agregada de carne bovina e a exportação total agregada de carne bovina para terceiros países (não membros da Comunidade Europeia), para obter essa relação de consumo. Dessa forma, a mesma razão entre produção e importação é usada para o cálculo das TEs para todos os produtos analisados.

O custo de transporte, seguro e transação $\left(\mathrm{IT}_{\mathrm{R}}\right.$, aqui denominado apenas custo de transporte) é obtido pela diferença entre os valores médios unitários CIF e FOB para o comércio entre Brasil e UE de carne bovina desossada, fresca ou refrigerada e de carne bovina desossada, congelada. As duas razões CIF e FOB calculadas para cada ano analisado, para as duas categorias de produtos mencionadas, são adotadas como custo de transporte também na estimação das TEs para as demais carnes frescas e congeladas. Por fim, $\alpha_{i}$ representa a preferência do consumidor, cuja escolha é arbitrada, e $\sigma$ é a elasticidade de Armington estimada. A seguir, apresenta-se um quadro-síntese das variáveis utilizadas.

Para realizar a estimação das elasticidades, adota-se uma análise de séries temporais, de modo que se deve iniciar avaliando individualmente as séries utilizadas, a fim de verificar se são estacionárias ou não (têm ou não raiz unitária). Seguindo Enders (2010), os primeiros testes feitos são os de Akaike (AIC) e Schwarz (SBC) para definição do modelo de quantidades importadas e preço médio de importação. Em seguida, o teste de Dickey-Fuller é aplicado às séries de dados, já transformadas em logaritmos ${ }^{6}$, para verificar a estacionaridade da série.

As séries para estimar a elasticidade de substituição entre UE e Brasil são a LQUANT, referente ao logaritmo da razão entre a quantidade importada pela UE-27 com origem nos países da UE-27 e a quantidade importada pela UE-27 com origem no Brasil, e a LPRECO, que apresenta a razão entre o preço médio das importações de carne pela UE-27 originadas do Brasil e o preço médio da carne importada pela UE-27 com ori-

6. Para mais detalhes sobre os testes, ver Enders (2010). 
Quadro 1. Síntese das variáveis e proxies utilizadas no modelo

\begin{tabular}{|c|c|c|c|c|}
\hline Variáveis ou Proxies & Variáveis utilizadas no cálculo das proxies & Periodicidade & Unidade & Fonte \\
\hline \multirow{2}{*}{$\begin{array}{l}\text { Valor médio unitário } \\
\left(\mathrm{p}_{\mathrm{lit}} \text { e } \mathrm{p}_{\mathrm{Dit}}\right)\end{array}$} & Quantidade importada ( $\mathrm{q}_{\mathrm{Iit}}$ e $\left.\mathrm{q}_{\mathrm{Dit}}\right)$ & Mensal (jan/99 a dez/2010) & $\mathrm{kg}$ & Eurostat \\
\hline & Valor importado & Mensal - jan/99 a dez/2010 & $€$ & Eurostat \\
\hline Taxa de câmbio média & - & Mensal - jan/99 a dez/2010 & US\$/€ & Eurostat \\
\hline \multirow[t]{2}{*}{ Preço doméstico $\left(\mathrm{p}_{\mathrm{D}}\right)$} & Quantidade importada pela UE & Anual - 2000 a 2010 & $\mathrm{~kg}$ & UN Comtrade \\
\hline & Valor importado pela UE & Anual - 2000 a 2010 & US\$ & UN Comtrade \\
\hline \multirow[t]{2}{*}{ Preço CIF ( $\left.\mathrm{p}_{\mathrm{CIF}}\right)$} & $\begin{array}{l}\text { Quantidade importada pelos } 50 \text { maiores países } \\
\text { compradores }\end{array}$ & Anual - 2000 a 2010 & $\mathrm{~kg}$ & UN Comtrade \\
\hline & $\begin{array}{l}\text { Valor importado pelos } 50 \text { maiores países com- } \\
\text { pradores }\end{array}$ & Anual - 2000 a 2010 & US\$ & UN Comtrade \\
\hline \multirow[t]{2}{*}{ Preço mundial $\left(\mathrm{p}^{*}\right)$} & $\begin{array}{l}\text { Quantidade importada pelos principais países } \\
\text { compradores (exceto UE) }\end{array}$ & Anual - 2000 a 2010 & $\mathrm{~kg}$ & UN Comtrade \\
\hline & $\begin{array}{l}\text { Valor importado pelos principais países com- } \\
\text { pradores (exceto UE) }\end{array}$ & Anual - 2000 a 2010 & US\$ & UN Comtrade \\
\hline \multirow{2}{*}{$\begin{array}{l}\text { Volume de venda pro- } \\
\text { dutos domésticos (D) }\end{array}$} & Produção total agregada & Anual - 2000 a 2010 & $1.000 \mathrm{t}$ & Eurostat \\
\hline & Exportação total agregada & Anual - 2000 a 2010 & $1.000 \mathrm{t}$ & Eurostat \\
\hline $\begin{array}{l}\text { Volume de produtos } \\
\text { importados (I) }\end{array}$ & - & Anual - 2000 a 2010 & $1.000 \mathrm{t}$ & Eurostat \\
\hline \multirow[t]{2}{*}{ Custo de transporte $\left(\mathrm{IT}_{\mathrm{R}}\right)$} & Quantidade comercializada entre UE e Brasil & Anual - 2000 a 2010 & US\$ & UN Comtrade \\
\hline & Valor comercializado entre UE e Brasil (CIF e FOB) & Anual - 2000 a 2010 & $\mathrm{~kg}$ & UN Comtrade \\
\hline
\end{tabular}

Fonte: Elaborado pelas autoras.

gem nos países do próprio bloco. Os subscritos $\mathrm{F}$ e C são utilizados para indicar, respectivamente, carnes frescas e congeladas.

Os testes de raiz unitária indicam presença de raiz unitária na série de preços e ausência na série de quantidades importadas para as carnes bovinas frescas, e seus resultados constam no Anexo A. Após realizar alguns testes do modelo com séries em nível e séries nas diferenças, adota-se o modelo de estimação das TE com as variáveis LQUANT $_{F}$ e LPRECOF $_{F}$ em nível, com a vantagem de facilitar a interpretação dos resultados. A elasticidade obtida para esse período, para carnes frescas, é de 0,54 , indicando que a carne bovina brasileira e europeia não são boas substitutas no mercado europeu.

Os mesmos testes são conduzidos para os dados de carnes congeladas e apontam que tanto LQUANT $_{C}$ quanto LPRECO $_{C}$ apresentam raiz unitária, como pode ser observado também no Anexo A, de modo que as variáveis são testadas para cointegração pela metodologia de EngleGranger (ENDERS, 2010). Obtém-se, então, que a estatística-t para o coeficiente $\alpha_{1}$ é igual a -3,0287, quando se analisam os resíduos da regressão linear de LQUANT $_{C}$ em função da constante e do LPRECO $_{C}$; e igual a -2,5949 quando se analisam os resíduos da regressão linear de $\mathrm{LPRECO}_{\mathrm{C}} \mathrm{em}$ função da constante e do LQUANT . Em qualquer um dos casos, a estatística-t obtida é inferior (em módulo) ao módulo do valor crítico de -3,77 (1\% de significância); portanto, as variáveis são não cointegradas.

Nesse caso, a elasticidade é, então, estimada na primeira diferença, obtendo-se $\beta=0,2869$ entre as importações europeias com origem na UE e no Brasil para carnes bovinas congeladas. Além da dificuldade de interpretar tal coeficiente, estimado com as séries nas diferenças dos logaritmos, destaca-se que o mesmo não é significativo nem a $15 \%$. Diante dos resultados acima, assume-se a mesma elasticidade encontrada para carnes frescas, de 0,54, para a estimação das tarifas equivalentes no comércio de carnes congeladas.

\section{Resultados}

A Tabela 1 apresenta resultados para as tarifas equivalentes calculadas para as MNTs que a carne 
bovina brasileira enfrenta na UE, pressupondo que o consumidor europeu tem preferência pela carne produzida nos países do bloco (ou seja, $\alpha>$ $0,5)$, e que a carne brasileira e europeia são heterogêneas entre si $(\sigma=0,54)$.

Considera-se preferência pelo produto doméstico, pois, segundo Bilkey e Nes (1982 apud KNIGHT, 1999), os consumidores têm a tendência de avaliar o produto do seu próprio país de maneira mais favorável do que os produtos estrangeiros. Além disso, alguns estudos (MAHESWARAN, 1994 apud KNIGHT, 1999) afirmam que consumidores tendem a esteriotipar produtos fabricados em países estrangeiros, e que, devido a estereótipos negativos e a sentimentos patrióticos sobre produtos nacionais, os consumidores estão mais propensos a preferir as mercadorias produzidas domesticamente.

Dessa forma, estima-se a tarifa equivalente considerando diferentes valores de $\alpha$, quais sejam $\alpha=0,6, \alpha=0,7$ e $\alpha=0,8$ representando a preferência pelo consumo de carnes produzidas domesticamente (Tabela 1). Destaca-se, com relação aos bens analisados, que as carnes que se destacam no comércio do Brasil com a UE são as carnes desossadas, congeladas e frescas.

Observa-se que as tarifas equivalentes, em geral, reduziram-se de 2001 a 2006, e a partir desse ano tornaram a aumentar. Nesse período, também se observa um aumento nos preços pagos para alguns produtores de carne bovina, como mostrado na Figura 2.

Tabela 1. Tarifas equivalentes das MNTs impostas pela UE para a carne bovina desossada* brasileira, considerando $\sigma=0,54$ e diferentes $\alpha$. (Em \%) $2000-2010$

\begin{tabular}{|c|c|c|c|c|c|c|}
\hline \multirow{2}{*}{ Ano } & \multicolumn{3}{|c|}{ Carne desossada, fresca ou refrigerada (\%) } & \multicolumn{3}{|c|}{ Carne desossada, congelada $(\%)$} \\
\hline & 0,6 & 0,7 & 0,8 & 0,6 & 0,7 & 0,8 \\
\hline 2000 & 487,94 & 287,2 & 136,64 & 447,65 & 251,21 & 103,88 \\
\hline 2001 & 462,41 & 260,94 & 109,84 & 473,19 & 264,23 & 107,51 \\
\hline 2002 & 280,98 & 142,15 & 38,03 & 257,82 & 133,34 & 39,98 \\
\hline 2003 & 424,54 & 258,07 & 133,21 & 343,99 & 194,06 & 81,60 \\
\hline 2004 & 324,15 & 191,98 & 92,85 & 276,03 & 151,10 & 57,40 \\
\hline 2005 & 301,43 & 173,33 & 77,27 & 238,59 & 128,55 & 46,03 \\
\hline 2006 & 187,89 & 87,37 & 11,97 & 138,37 & 60,18 & 1,53 \\
\hline 2007 & 222,84 & 112,72 & 30,13 & 244,07 & 124,23 & 34,35 \\
\hline 2008 & 348,91 & 198,25 & 85,25 & 389,23 & 213,25 & 81,27 \\
\hline 2009 & 247,44 & 128,65 & 39,55 & 263,75 & 135,70 & 39,66 \\
\hline 2010 & 351,92 & 198,88 & 84,10 & 325,64 & 172,07 & 56,89 \\
\hline
\end{tabular}

* Os resultados para as carnes não desossadas foram colocadas no Anexo B, devido à baixa importância dessas carnes nas exportações brasileiras. Fonte: Resultados do trabalho.

Figura 2. Evolução dos preços ao produtor para carne bovina em países selecionados aftósicos e não aftósicos, em dólares por tonelada. Anos de 2000 a 2010*

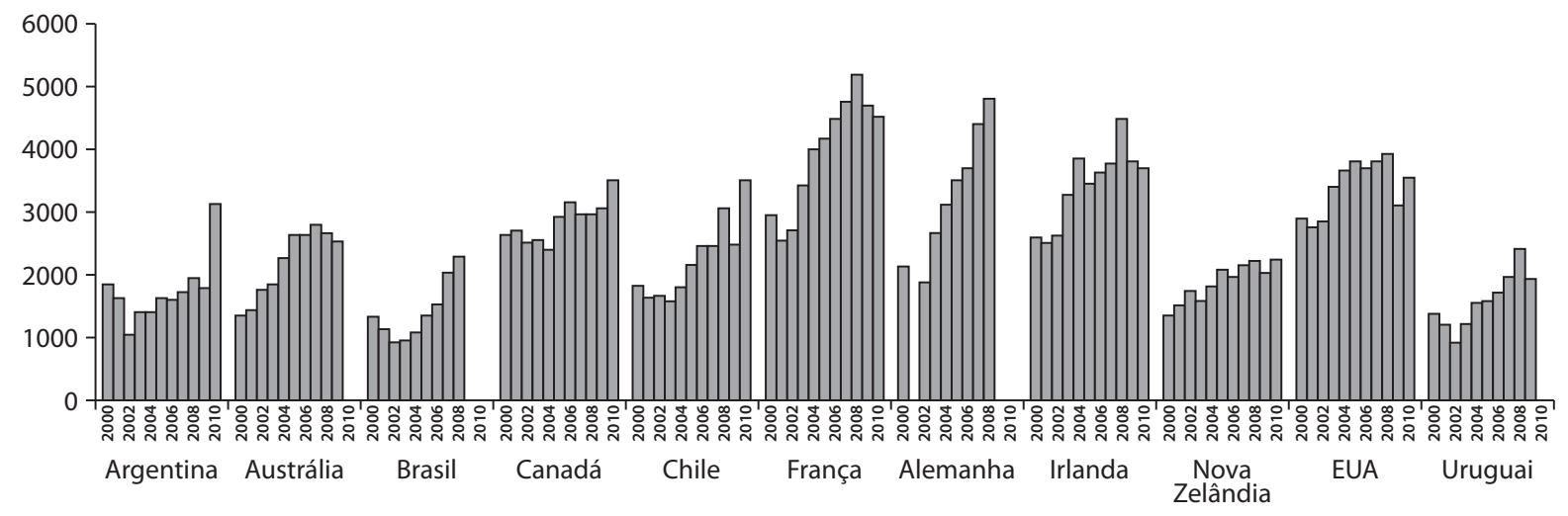

* Para 2009 e 2010, não há disponibilidade de dados para Brasil e Alemanha e, para 2010, não há disponibilidade para Austrália e Estados Unidos. Fonte: FAO Statistics - elaborado pelas autoras. 
Verifica-se, ainda, que, com o aumento do parâmetro $\alpha$, representando maior preferência pela carne de origem doméstica, os valores observados para as tarifas equivalentes diminuem. Dessa forma, pode-se afirmar que as pressuposições sobre as preferências do consumidor europeu quanto à carne interferem significativamente nos resultados. Deste modo, uma boa estimação também para esse parâmetro é bastante importante para que tarifas equivalentes mais representativas do mercado de carne europeu sejam obtidas. Ainda nesse contexto, Yue, Beghin e Jensen (2005) afirmam que essa questão gera implicações às análises gravitacionais que normalmente assumem $\alpha=0,5$, ou seja, indiferença entre bens domésticos e importados. Neste trabalho, também foram estimadas as tarifas equivalentes, assumindo que não há preferência pela carne europeia, podendo ser verificado pela Figura 3 que essa pressuposição implica tarifas equivalentes de maior magnitude do que quando há certa preferência pelo bem doméstico.

Os resultados finais obtidos a partir da simulação de valores diferentes para o parâmetro de preferência do consumidor $(\alpha)$ apontam tarifas equivalentes bastante altas em alguns casos e anos, o que sugere que, além do efeito do imposto de importação, o preço da carne brasileira no mercado europeu também é afetado por exigências não tarifárias. Essas tarifas equivalen- tes são decorrentes da alta quantidade de medidas impostas às importações de carne pela UE, como apresentado por Schlueter e Wieck (2009) e Kassum e Morgan (2002) e são condizentes com o esperado, visto que, como exposto por Roberts, Josling e Orden (1999), a imposição de uma MNT terá efeito nos preços, e essa diferença pode ser captada pelo método do price-wedge. Destaca-se, contudo, que, embora essas tarifas sejam um forte indicador dos impactos causados pelas MNTs, tendo inclusive apresentado variações condizentes com a imposição de novas medidas, sua magnitude deve ser usada com cautela, visto que, devido à indisponibilidade de dados, tenham sido utilizadas proxies para os preços.

Além disso, constatam-se algumas tarifas equivalentes negativas, principalmente quando se assume $\alpha=0,8$, o que significa que, à medida que a preferência pelo produto europeu cresce em relação à carne brasileira, o efeito de medidas não tarifárias deixaria de existir, indicando mesmo uma "desproteção" para a carne doméstica em relação à importada. Assim, à medida que se pressupõe que os bens são heterogêneos, passa-se a ter a necessidade de estudos que estimem este grau de preferência e as elasticidades de substituição, para que os modelos de comércio possam, de fato, refletir melhor os efeitos das medidas não tarifárias e distinguir a influência da preferência dos consumidores.

Figura 3. Tarifas Equivalentes para as principais carnes exportadas do Brasil para a UE, considerando indiferença dos consumidores $(\alpha)$ e preferência pela carne doméstica $(\alpha=0,70)$. Em \% . 2000-2010

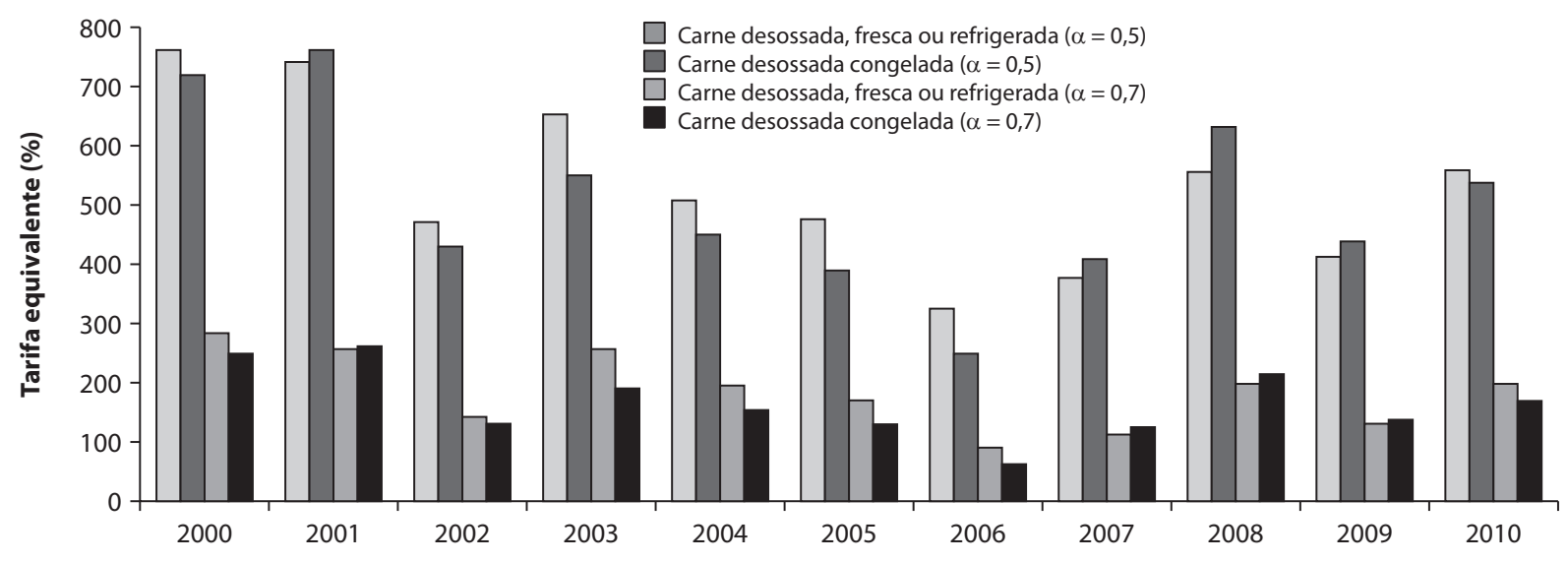

Fonte: Resultados do trabalho. 


\section{Conclusões}

Neste trabalho, estimam-se as tarifas equivalentes para medidas não tarifárias, assumindo-se que consistem particularmente de requisitos técnicos e sanitários no caso das carnes bovinas, impostos pela UE sobre as exportações brasileiras. Primeiramente, a partir da literatura, observa-se que existem diversas exigências legais e normas que incidem sobre essas exportações, principalmente com relação à rastreabilidade dos produtos e à prevenção de disseminação de doenças. No caso das exportações brasileiras de carne, segundo a literatura, estas são particularmente sensíveis ao tratamento que os países compradores dão à questão da febre aftosa.

Embora os economistas agrícolas empreguem diferentes métodos para avaliar o impacto dessas medidas não tarifárias sobre os fluxos comerciais, ainda há avanços necessários. Tarifas equivalentes são estimadas por autores principalmente com o intuito de utilizá-las como variáveis explanatórias em modelos mais sofisticados, que buscam também incorporar a heterogeneidade dos bens como elemento determinante do comércio. No entanto, estimativas dessas tarifas, considerando bens heterogêneos, não estão disponíveis na literatura nacional, e é essa lacuna que este artigo pretende ajudar a preencher, pois as tarifas estimadas podem ser utilizadas em modelos mais complexos de comércio, para incorporar o impacto da incorporação dessas medidas.

A identificação da existência dessas restrições técnicas e sanitárias e do levantamento pormenorizado de suas características é importante neste trabalho, pois a metodologia price-wedge empregada para mensurá-las não permite sua identificação, mas apenas a quantificação de um efeito que lhe é atribuído. As estimativas apontam, em geral, para tarifas equivalentes elevadas, tanto para carnes frescas quanto para as congeladas, no período de 2000 a 2010. Isso significa que o preço doméstico da UE e o preço mundial realmente diferem, como antecipado por Roberts, Josling e Orden
(1999) e Beghin e Bureau (2001), o que pode indicar que o mercado europeu tem sido protegido não apenas por tarifas, mas também por medidas não tarifárias, como as exigências técnicas e sanitárias. Contudo, este resultado deve ser analisado com cautela, o que pode ser considerado uma limitação das conclusões, tendo em vista a dificuldade de serem obtidos preços de carne bovina representativos da cotação mundial e valores para a carne bovina no mercado europeu. Essa baixa disponibilidade de dados pode ser considerada a principal limitação do estudo, pois fez com que fosse necessária a utilização de proxies. Diante disso, as magnitudes das TEs podem não ter muita relevância na análise, sendo que, no entanto, as variações possam ser um bom indicador do impacto das medidas, podendo inclusive ser utilizadas em modelos econométricos.

Além disso, observa-se que, na estimação das tarifas equivalentes, os valores do parâmetro que indica preferência do consumidor afetam as tarifas equivalentes obtidas. À medida que a preferência do consumidor se volta crescentemente ao bem doméstico, há uma redução na tarifa equivalente estimada, que pode, inclusive, tornar-se negativa, indicando desproteção ao produto interno.

Apesar de a carne bovina ser o foco deste trabalho, existem outros produtos agrícolas brasileiros exportáveis que também enfrentam exigências técnicas, e sanitárias e há uma preocupação crescente a respeito dessas medidas tornarem-se cada vez mais frequentes e restritivas ao comércio. Dessa forma, a estimação da tarifa equivalente é uma ferramenta que pode melhorar modelos econométricos e também de equilíbrio geral nas aplicações sobre o comércio, ao permitir a incorporação dos efeitos das MNTs na análise de padrões de comércio e impactos de negociações. No entanto, ter acesso ou organizar bases de dados detalhadas sobre preços e demais parâmetros necessários é essencial para obter estimativas mais exatas e aplicáveis ao acompanhamento e análise dos mercados. 


\section{Referências bibliográficas}

ANDRIAMANANJARA, S. et al. The effects of non-tariff measures on prices, trade and welfare: CGE implementation of policy-based price comparisons. Working Paper 2004-04-A - Office of Economics Working Paper, U.S. International Trade Commission, abr. 2004. Disponível em: < http://www.usitc.gov/publications/332/working papers/EC200404A.pdf> . Acesso em: 03 mar. 2010.

ASHMEAD, R. A comparison of food safety and animal health systems in the US, Canada, Australia, the EU, and the $U K$ - Final Report. Serecon Management Consulting Inc., 2008. Disponível em: <http://www.iconebrasil. org.br/pt $/$ act $\mathrm{A}=8 \&$ areaID $=7 \&$ secaoID $=20 \&$ artig $\mathrm{oID}=1635>$. Acesso em: 16 ago. 2010.

BEGHIN, J. C. Nontariff barriers. Working Paper 06-WP 438 - Center for Agricultural and Rural Development, Iowa State University, dez. 2006. Disponível em: <http://www.card.iastate.edu/publications/DBS/ PDFFiles/06wp438.pdf > . Acesso em: 15 mar. 2010.

BEGHIN, J. C. e BUREAU, J. C. Quantification of sanitary, phytosanitary, and technical barriers to trade for trade policy analysis. Working Paper 01-WP 291 - Center for Agricultural and Rural Development, Iowa State University, dez. 2001. Disponível em: <http://www. econ.iastate.edu/research/webpapers/paper_2024. pdf $>$. Acesso em: 09 fev. 2010.

BILKEY, W. e NES, E. Country of origin effects on product evaluations. Journal of International Business Studies, v. 13, Spring/Summer 1982, p. 89-99.

BRADFORD, S. Paying the price: final goods protection in OECD countries. The Review of Economics and Statistics, Cambridge, v. 85, n. 1, 2003. Disponível em: $<$ http://www.mitpressjournals.org/doi/pdf/10.1162/00 3465303762687686> . Acesso em: 12 mar. 2010.

CALVIN, L. e KRISSOFF, B. Technical barriers to trade: a case study of phytosanitary barriers and U.S.-Japanese Apple trade. Journal of Agricultural and Resource Economics, Fargo, v. 23, n. 2, 1998. Disponível em: < http:// ageconsearch.umn.edu/bitstream/31191/1/23020351. pdf > . Acesso em: 09 fev. 2010.

CUNHA FILHO, J. H. Impactos econômicos de medidas técnicas impostas às exportações de carne de frango brasileira. Série Estudos de Comércio Internacional, n. 1 - Centro de Estudos Avançados em Economia Aplicada, Escola Superior de Agricultura "Luiz de Queiroz", Universidade de São Paulo, 2006. Disponível em: <http://www.cepea.esalq.usp.br/pdfs/146.pdf > . Acesso em: 19 maio 2010.
DEARDORFF, A. V. e STERN, R. M. Measurement of non-tariff barriers. Working Paper n. 129 - Economics Department, Organisation for Economic Co-operation and Development (OCDE), 1997. Disponível em: $<$ http://www.oecd.org/dataoecd/34/3/1863859.pdf>. Acesso em: 05 fev. 2010.

DISDIER, A. C., FONTAGNÉ, L. e MIMOUNI, M. The impact of regulations on agricultural trade: evidence from SPS and TBTs Agreements. Working Paper 200704 - Center D`Études Prospectives Et D`Informations Internationales(CEPII), fev.2007. Disponívelem: <http:// www.cepii.fr/anglaisgraph/workpap/summaries/2007/ wp07-04.htm >. Acesso em: 04 mar. 2010.

ENDERS, W. Applied econometric time series. 3. ed. Hoboken: Wiley, 2010. 517 p.

EUROSTAT. Comissão Européia. Estatísticas. Disponível em: $\quad<$ http://epp.eurostat.ec.europa.eu/portal/page/ portal/statistics/themes > . Acesso em: fev. 2011.

FAO. Estatísticas (FAOStat), 2000-2009. Disponível em: $<$ http://faostat.fao.org/>. Acesso em: 17 jan. 2010.

GALLAWAY, M. P., MCDANIEL, C. A. e RIVERA S. A. Short-run and long-run industry-level estimates of U.S. Armington elasticities. The North American Journal of Economics and Finance, Amsterdam, v. 14, 2003. Disponível em: <https://www.gtap.agecon.purdue. edu/resources/download/1338.pdf $>$. Acesso em: 08 ago. 2010.

KASSUM, J. e MORGAN, N. The SPS Agreement: livestock and meat trade. 2002. 16 p. (Draft: not for dissemination).

KNIGHT, G. A. Consumer preferences for foreign and domesticproducts.JournalofConsumerMarketing,Arwada, v. 16, n. 2, 1999, p. 151-162. Disponível em: < http://www. emeraldinsight.com/10.1108/07363769910260524>. Acesso em: 27 set. 2011.

KEE, H. L., NICITA, A. e OLARREAGA, M. Estimating trade restrictiveness indices, 2008. Disponível em: $<$ http:// siteresources.worldbank.org/INTRES/Resources/ OTRIpaper.pdf>. Acesso em: 10 mar. 2010.

LIMA, R. C. A. e BARRAL, W. Barreiras não tarifárias ao comércio: o papel regulatório da OMC, controvérsias e novas restrições. Revista Brasileira de Comércio Exterior, Rio de Janeiro, n. 93, 2007. Disponível em: < http://www. funcex.com.br/rbce.asp > . Acesso em: 08 mar. 2010.

MAHESWARAN, D. Country of origin as a stereotype: effects of consumer expertise and attribute strength on product evaluations. Journal of Consumer Research, v. 21, set. 1994, p. 354-65. 
MASKUS, K. E. e WILSON, J. S. A review of past attempts and the new policy context. In: Quantifying the impact of technical barriers to trade: can it be done?. Ann Arbor: The University of Michigan Press, 2001, p. 1-27.

MDIC - Ministério do Desenvolvimento, Industria e Comércio, 2001?. Barreiras externas às exportações brasileiras - União Européia. Brasília: SECEX (Secretaria de Comércio Exterior), 2001?.81 p. Relatório. Disponível em: <http://www.desenvolvimento.gov.br/arquivos/ dwnl_1196773199.pdf>. Acesso em: 07 abr. 2010.

MDIC. Base de dados (Aliceweb). Disponível em: < http:// aliceweb2.mdic.gov.br/>. Acesso em: 07 abr. 2010.

MENDES, G. M., COELHO, A. B. e CAMPOS, A. C. Efeitos das barreiras não tarifárias impostas pela União Européia e pelos Estados Unidos sobre as exportações brasileiras de manga. In: CONGRESSO SOCIEDADE BRASILEIRA DE ECONOMIA E SOCIOLOGIA RURAL, 47., 2009, Porto Alegre. Anais... Disponível em: <http://www.sober.org.br/palestra/13/787.pdf > . Acesso em: 01 fev. 2010.

MIRANDA, S. H. G. e BARROS, G. S. C. The application of intervention models to non-tariff trade barriers: a case study of Brazilian beef exports. Journal of International Agricultural Trade and Development, New York, v. 5, n. 2, p. 255-272, 2009.

NIMENYA, N. Quantifying non-tariff measures in international agricultural trade: a tariff equivalent of food safety standards on European fish and horticultural imports from Africa countries, 2009.

PITELLI, M. M. Sistema agroindustrial brasileiro da carne bovina: análise do impacto das mudanças institucionais européias sobre a estrutura de governança. 2004. 160 p. Dissertação (Mestrado em Economia Aplicada) Escola Superior de Agricultura "Luiz de Queiroz", Universidade de São Paulo, Piracicaba, 2004.

ROBERTS, D., JOSLING, T. E. e ORDEN, D. A framework for analyzing technical trade barriers in agricultural markets. Market and Trade Economics Division, Economic Research Service, U.S. Department of Agriculture. Washington, 1999. Technical Bulletin, n. 1876. Disponível em: <http://www.ers.usda.gov/ Publications/TB1876/> . Acesso em: 17 mar. 2010.

SCHLUETER, S. W. e WIECK, C. Regulatory SPS Instruments in Meat Trade. In: IATRC Annual Meeting "Private Standards and Non-Tariff Barriers:
Measurement, Impacts, and Legal Issues", 2009, Fort Myers, Florida. Disponível em: < http://iatrc.software. umn.edu/activities/annualmeetings/themedays/ pdfs/2009Dec-Wieck.pdf> . Acesso em: 23 jan. 2011.

SOUZA, M. J. P. e BURNQUIST, H. L. Importância das exigências técnicas à exportação de empresas brasileiras. In: CONGRESSO DA SOCIEDADE BRASILEIRA DE ECONOMIA, ADMINISTRAÇÃO E SOCIOLOGIA RURAL, 46., 2008, Rio Branco. Anais... Disponível em: $<$ http://www.sober.org.br/palestra/9/358.pdf $>$. Acesso em: 22 jun. 2010.

TOURINHO, O. A. F., KUME, H. e PEDROSO, A. C. S. Elasticidades de Armington para o Brasil: 1986-2001. Texto para Discussão, n. 901 - Instituto de Pesquisa Econômica Aplicada (IPEA), 2002. Disponível em: $<$ http://www.ipea.gov.br/portal/images/stories/PDFs/ TDs/td_0901.pdf >. Acesso em: 27 set. 2011.

\section{UNITED NATIONS COMMODITY TRADE STATISTICS} DATABASE (UN Comtrade). Disponível em: <http:/ comtrade.un.org/db/default.aspx>. Acesso em: $20 \mathrm{abr}$. 2010.

UNITED NATIONS CONFERENCE ON TRADE AND DEVELOPMENT (UNCTAD). 2005. Methodologies, classifications, quantification and development impacts of non-tariff barriers: note by the UNCTAD Secretariat, Document TD/B/COM.1/EM.27/2, jun. 2005. Disponível em: $\quad<$ http://www.unctad.org/en/docs/c1em27d2 en.pdf $>$. Acesso em: 04 mar. 2010.

USDA - United States Department of Agriculture. Disponível em: <http://www.usda.gov/wps/portal/ usda/usdahome >. Acesso em: 05 jan. 2011.

VIEGAS, I. F. P. Impactos das barreiras comerciais dos Estados Unidos e União Européia sobre a pauta de exportações agrícolas brasileiras. 2003. 68 p. Dissertação (Mestrado em Economia Aplicada) - Escola Superior de Agricultura "Luiz de Queiroz", Universidade de São Paulo, Piracicaba, 2003. Disponível em: < http://www. teses.usp.br/teses/disponiveis/11/11132/tde-17122003102113 /publico/isabel.pdf >. Acesso em: 08 mar. 2010.

YUE, C., BEGHIN, J.C. e JENSEN, H. H. Tariff equivalent of technical barriers to trade with imperfect substitution and trade costs. Working Paper 05-WP 383 - Center for Agricultural and Rural Development, Iowa State University, nov. 2005. Disponível em: <http://www. card.iastate.edu/publications/DBS/PDFFiles/05wp33. pdf >. Acesso em: 01 fev. 2010. 
Anexo A. Análise estatística para determinação da elasticidade de Armington

Estimam-se, então, as regressões para três casos distintos: (1) Modelo com tendência e constante; (2) Modelo sem tendência e com constante; (3) Modelo sem tendência e sem constante. Os resultados podem ser verificados na tabela apresentados a seguir.

Tabela 1A. Resultados dos testes de raiz unitária realizados para a estimação do modelo, para as variáveis LQUANT $_{\mathrm{F}}$ e LPRECO

\begin{tabular}{|c|c|c|c|c|c|c|}
\hline & \multicolumn{2}{|c|}{ Caso 1} & \multicolumn{2}{|c|}{ Caso 2} & \multirow{2}{*}{$\begin{array}{c}\text { Caso } 3 \\
\tau^{1} \\
\end{array}$} & \multirow{2}{*}{$\mathrm{I}(\mathrm{d})$} \\
\hline & $\tau_{\tau}$ & $\phi_{3}$ & $\tau_{\mu}$ & $\phi_{1}^{1}$ & & \\
\hline LQUANT $_{\mathrm{F}}\{1\}$ & $-3,9599$ & 8,4771 & $-3,5707$ & - & - & $\mathrm{I}(0)$ \\
\hline $\operatorname{LPRECO}_{\mathrm{F}}\{1\}$ & $-2,2702$ & 2,9350 & $-1,7941$ & 1,6173 & $-0,8418$ & $\mathrm{I}(1)$ \\
\hline
\end{tabular}

Nota: Valores críticos ( $\mathrm{n}^{\mathrm{o}}$ obs. $=100, \alpha=1 \%$ ): $\tau_{\tau}=-4,04, \phi_{3}=8,73, \tau_{\mu}=-3,51, \phi_{1}=6,70, \tau=-2,60$.

${ }^{1}$ Para LQUANT $\mathrm{F}$ não se obtém o $\phi_{1}$ e o $\tau$, pois conclui-se que a série não possui raiz unitária após excluir a tendência que não é significativa (primeiro passo do Caso 2).

Fonte: Resultados do trabalho.

Tabela 2A. Resultados para elasticidade de Armington no mercado europeu de carnes bovinas frescas entre a carne importada europeia e a carne brasileira (variáveis em nível)

\begin{tabular}{cccc}
\hline Variável & Coeficiente & Estatística-t & Significância \\
\hline Constante & 0,609241 & 4,2755 & 0,000035 \\
LPRECO $_{\mathrm{F}}$ & 0,543387 & 2,9545 & 0,003679 \\
LQUANT $_{\mathrm{F}}\{1\}$ & 0,782147 & 17,3870 & 0,000000 \\
dummy & 0,445861 & 2,4775 & 0,014430 \\
\hline
\end{tabular}

Fonte: Resultados do trabalho.

Realizam-se, então, os testes para os dados referentes às carnes congeladas, representadas pelo C subscrito, após o nome das variáveis.

Tabela 3A. Resultados dos testes de raiz unitária realizados para a estimação do modelo, para as variáveis LQUANT $_{C}$ e LPRECO

\begin{tabular}{|c|c|c|c|c|c|c|}
\hline & \multicolumn{2}{|c|}{ Caso 1} & \multicolumn{2}{|c|}{ Caso 2} & \multirow{2}{*}{$\begin{array}{c}\text { Caso } 3 \\
\tau\end{array}$} & \multirow{2}{*}{$\mathrm{I}(\mathrm{d})$} \\
\hline & $\tau_{\tau}$ & $\phi_{3}$ & $\tau_{\mu}$ & $\phi_{1}$ & & \\
\hline LQUANT $_{\mathrm{C}}\{1\}$ & $-1,2643$ & 2,7652 & $-2,7988$ & 4,3056 & $-0,6447$ & $\mathrm{I}(1)$ \\
\hline $\operatorname{LPRECO}_{\mathrm{C}}\{1\}$ & $-1,6686$ & 2,5835 & $-1,2743$ & 0,8249 & $-1,1725$ & $\mathrm{I}(1)$ \\
\hline
\end{tabular}

Nota: Valores críticos (no obs. $=100, \alpha=1 \%$ ): $\tau_{\tau}=-4,04, \phi_{3}=8,73, \tau_{\mu}=-3,51, \phi_{1}=6,70, \tau=-2,60$.

Fonte: Resultados do trabalho.

Tabela 4A. Resultados para elasticidade de substituição no mercado europeu de carnes bovinas congeladas entre a carne importada europeia e a carne brasileira (variáveis na primeira diferença)

\begin{tabular}{cccc}
\hline Variável & Coeficiente & Estatística-t & Significância \\
\hline DLPRECO $_{\mathrm{C}}$ & 0,286989 & 1,3873 & 0,167568 \\
DLQUANT $_{\mathrm{C}}\{1\}^{1}$ & $-0,309737$ & $-3,8746$ & 0,000163 \\
\hline
\end{tabular}

${ }^{1}$ Variável diferenciada, no lag 1.

Fonte: Resultados do trabalho. 
Anexo B. Tarifas equivalentes das MNTs impostas pela UE para a carne bovina com osso brasileira, considerando $\sigma=0,54$ e diferentes $\alpha_{\mathrm{i}}$. (Em \%) 2000-2010*

\begin{tabular}{|c|c|c|c|c|c|c|}
\hline \multirow{2}{*}{ Ano $\alpha$} & \multicolumn{3}{|c|}{ Carcaça ou meia-carcaça, fresca ou refrigerada (\%) } & \multicolumn{3}{|c|}{ Outras peças não desossadas, frescas ou refrigeradas (\%) } \\
\hline & 0,6 & 0,7 & 0,8 & 0,6 & 0,7 & 0,8 \\
\hline 2000 & 709,09 & 420,84 & 204,65 & 508,59 & 289,02 & 124,35 \\
\hline 2001 & 474,65 & 286,17 & 144,82 & 686,85 & 396,09 & 178,02 \\
\hline 2002 & 252,67 & 118,93 & 18,62 & 419,18 & 241,20 & 107,72 \\
\hline 2003 & 220,31 & 116,76 & 39,09 & 433,63 & 255,31 & 121,57 \\
\hline 2004 & 250,48 & 132,06 & 43,24 & 294,93 & 162,46 & 63,11 \\
\hline 2005 & 226,8 & 121,36 & 42,27 & 248,43 & 111,82 & 9,35 \\
\hline 2006 & 98,81 & 35,62 & $-11,77$ & 195,12 & 106,44 & 39,93 \\
\hline 2007 & 114,09 & 43,09 & $-10,15$ & 208,63 & 113,86 & 42,79 \\
\hline 2008 & 159,31 & 67,71 & $-0,99$ & 283,63 & 162,24 & 71,17 \\
\hline 2009 & 192,42 & 104,62 & 38,77 & 298,51 & 171,95 & 77,03 \\
\hline 2010 & 208,68 & 99,30 & 17,26 & 296,44 & 152,65 & 44,81 \\
\hline$\alpha$ & \multicolumn{3}{|c|}{ Carcaça ou meia-carcaça, congelada (\%) } & \multicolumn{3}{|c|}{ Outras peças não desossadas, congeladas (\%) } \\
\hline Ano & 0,6 & 0,7 & 0,8 & 0,6 & 0,7 & 0,8 \\
\hline 2000 & 893,52 & 474,26 & 159,81 & 199,56 & 96,67 & 19,5 \\
\hline 2001 & $1.082,22$ & 650,50 & 326,71 & 869,25 & 517,57 & 253,81 \\
\hline 2002 & 972,81 & 590,28 & 303,37 & 909,64 & 557,99 & 294,26 \\
\hline 2003 & $1.492,83$ & 921,63 & 493,24 & $1.084,46$ & 675,96 & 369,59 \\
\hline 2004 & 912,38 & 554,29 & 285,72 & 747,04 & 454,05 & 234,30 \\
\hline 2005 & NA & NA & NA & 532,89 & 318,60 & 157,88 \\
\hline 2006 & 990,81 & 605,48 & 316,48 & 406,78 & 235,21 & 106,52 \\
\hline 2007 & 466,76 & 268,82 & 120,36 & 514,83 & 301,38 & 141,29 \\
\hline 2008 & 907,58 & 553,99 & 288,8 & 500,56 & 286,50 & 125,73 \\
\hline 2009 & 767,09 & 470,11 & 247,38 & 577,34 & 334,76 & 152,83 \\
\hline 2010 & 451,74 & 268,05 & 130,29 & 514,11 & 292,07 & 125,53 \\
\hline
\end{tabular}

* Alguns resultados para 2005 não foram calculados devido à indisponibilidade de dados.

Fonte: Resultados do trabalho. 
